\title{
Antimicrobial resistance among clinically relevant bacterial isolates in Accra: a retrospective study
}

\author{
Jibril Mohammed ${ }^{1}$, Yaovi Mahuton Gildas Hounmanou ${ }^{2}$ and Line Elnif Thomsen ${ }^{2 *}$
}

\begin{abstract}
Objective: The aim of this study was to determine the antimicrobial resistance pattern of bacterial isolates from different specimens at various hospitals and private diagnostic service laboratories in Ghana.

Results: A retrospective data of culture and sensitivity test results from 2016 were extracted from the microbiology record book of six laboratories in Accra, Ghana. The data included type of clinical specimen, sex of patient, name of bacterial isolate and antibiotic resistance profile. A total of 16.6\% $(n=10,237)$ resistant isolates were obtained, however, the proportions of resistant isolates varied significantly between laboratories. High resistance towards tetracycline, ampicillin, cotrimoxazole and cephalosporins, but low towards amoxiclav and aminoglycosides, was observed. This study identified E. coli and Staphylococcus species as the major resistant bacteria from clinical specimen in Accra and the highest prevalence of the isolates was found in urine specimens in all six laboratories $(69.1 \%, n=204 ; 52.6 \%$, $n=36 ; 52.3 \%, n=350 ; 37.9 \%, n=298 ; 53 \%, n=219 ; 62.1 \%, n=594)$ and in female patients $(81.4,50$ and $69.5 \%)$. Regular surveillance and local susceptibility pattern analysis is extremely important in selecting the most appropriate and effective antibiotic for the treatment of bacterial infections.
\end{abstract}

Keywords: Antimicrobial resistance, Clinical bacteria, Ghana

\section{Introduction}

One of modern medicine's greatest achievements has been the production of antimicrobials against diseasecausing microbes, but after more than 70 years of widespread use, these therapeutic agents have gradually lost their potency [1]. Antimicrobial resistance (AMR) is now a serious global health concern causing problems in the treatment and prevention of infections. Nevertheless, these microorganisms especially bacteria, causes some of the most common infections in different settings; in the community, in hospitals or transmitted through the food chain [2]. Antibiotics are among the most commonly prescribed drugs in hospitals and in developed countries about $30 \%$ of the hospitalized patients are treated with

\footnotetext{
*Correspondence: leth@sund.ku.dk

2 Department of Veterinary and Animal Sciences, Faculty of Health and Medical Sciences, University of Copenhagen, 1870 Frederiksberg, Denmark

Full list of author information is available at the end of the article
}

these drugs [3]. Antibiotic use in Africa is progressively on the rise and the availability of un-prescribed antibiotics is part of the problem. A study combining data from various African countries revealed that approximately $90.1 \%$ of cases of acute illness sought care outside the home and $36.2 \%$ took an antibiotic medication and over $30 \%$ of the individuals acquired antibiotics without prescription [4]. Several studies from various African countries have furthermore shown high levels of antibiotic resistant bacterial pathogens [5-9]. In spite of the ongoing research on antimicrobial resistance, there are still no indications that the situation is abating. In order to formulate an efficient AMR control plan, it is crucial to have a clear view on the current situation so as to determine when, how and where to initiate control measures. The present study assessed a 12 months trend of antimicrobial resistance in clinically relevant bacterial isolates in Accra, Ghana.

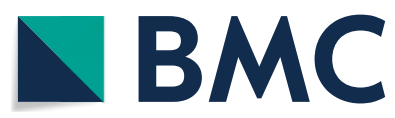

(c) The Author(s) 2018. This article is distributed under the terms of the Creative Commons Attribution 4.0 International License (http://creativecommons.org/licenses/by/4.0/), which permits unrestricted use, distribution, and reproduction in any medium, provided you give appropriate credit to the original author(s) and the source, provide a link to the Creative Commons license, and indicate if changes were made. The Creative Commons Public Domain Dedication waiver (http://creativecommons.org/ publicdomain/zero/1.0/) applies to the data made available in this article, unless otherwise stated. 


\section{Main text \\ Methods \\ Study design}

This study was a retrospective analysis of miscellaneous clinical samples that were tested for bacterial presence and subsequent susceptibility testing dated from January to December 2016, from six locations comprising three hospitals and three private diagnostic service laboratories. The study locations include Trust Specialist Hospital (TH), Holy Trinity Medical Center (HTMC), LA General Hospital (LAGH), Patholab Solutions (Ghana) Limited (PSGL), G2 Medical Laboratory and Mediplast Diagnostic Center (G2ML). All locations are situated in the city of Accra, Ghana and the data were sampled from January to May 2017.

\section{Data extraction}

The clinical information extracted from the six laboratories included type of sample analyzed, name of pathogens isolated and the names of antibiotics used for susceptibility testing and the susceptibility results as recorded in the laboratory report. All information were confirmed by each laboratory technician and reconfirmed by the chief biomedical scientist.

\section{Laboratory analysis, clinical samples and collection of bacterial isolates}

Several types of clinical samples were cultured, including urine, blood, sputum, urethral smear, pus and seminal fluid, and swabs from various body sites (vagina, ear, throat, umbilical cord, eye and wound). All the laboratories sampled for the current study employed similar standard microbiological culturing techniques.

\section{Bacterial identification}

All the laboratories performed similar microscopic identification as previously described [10]. For Grampositive cocci, tube coagulase and catalase were done for species differentiation. Further biochemical tests included lactose fermentation, indole, citrate utilization, urease and Triple Sugar Iron reaction to ascertain the biochemical characteristics of the Gram-negative isolates. Two of the laboratories (Trust Hospital and Mediplast Diagnostic Center) also deployed the BBL Crystal Panel Viewer (Becton-Dickinson Maryland, USA) for further identification of isolates.

\section{Antimicrobial susceptibility}

Antimicrobial susceptibility test were performed by all 6 laboratories using the Kirby-Bauer disk diffusion method [11] and interpreted using the Clinical Laboratory Standard Institute guidelines [12]. Gram-positive and Gram-negative antibiotic disks were selected for Gram-positive and Gram-negative bacterial isolates, respectively. Each laboratory used disks manufactured by Abtek Biologicals, UK and Biomark Laboratories, India. The disks and their concentrations in micrograms included: ampicillin (AMP: 10), cotrimoxazole (COT: 25), amoxiclav (AMC: 20/10), nalidixic acid (NAL: 30), tetracycline (TET: 30), ceftriaxone (CTR: 30), ceftazidime (CAZ: 30), nitrofurantoin (NIT: 300), gentamicin (GEN: 10), ciprofloxacin (CIP: 30), levofloxacin (LEV: 5), norfloxacin (NOR: 30), chloramphenicol (CHL: 10), cefuroxime (CRX: 30), amikacin (AMK: 30), piperacillin (PIP: 100), nitrofurantoin (NTD: 200), cefotaxime (CTX: 30), penicillin (P: 1.5), flucloxacillin (FLX: 1), erythromycin (ERY: 5), amoxicillin (AMX: 30), ofloxacin (OF: 5), cloxacillin (CLX: 5), perfloxacin (PEF: 10), augmentin (AUG: 30), vancomycin (VAN: 30), meropenem (MEM: 10), roxithromycin (RO: 15), sparfloxacin (SPX: 5), lincomycin (LM: 15), azithromycin (AZM: 15), pipemidic acid (PPA: 20).

\section{Data analysis}

Collected data was entered into Microsoft Excel and loaded into statistical package for social sciences (SPSS, version 20) for analysis. Proportions of predominant isolates and antibiotic resistance profiles were compared using Chi square test. The Pearson correlation test was used to assess associations among locations and isolates in relation to the resistance profile of the isolates at a critical probability $P<0.05$.

\section{Results}

Records on resistant bacterial isolates and the antibiotic resistant profile cultured from January to December 2016 in six microbiology laboratories were extracted. These laboratories include three hospitals namely Trust Hospital (TH), LA General Hospital (LAGH) and Holy Trinity Medical Center (HTMC) and three private diagnostic service laboratories, Mediplast Diagnostic Center (MDC), Patholab Solutions Ghana Limited (PSGL) and G2 Medical Laboratory (G2ML).

In the study period, a total of 10,237 samples were cultured and 1701 (16.62\%) resistant isolates were obtained. However, proportions of antibiotic resistant bacteria differed significantly from one laboratory to the other with PSGL samples generating the highest number of resistant isolates $(33.08 \%, \mathrm{P}<0.05)$, whereas isolates recovered at G2ML showed the lowest level of resistance $(5.51 \%$, $\mathrm{P}<0.05$ ) (Table 1).

Out of the six labs, nineteen different specimens were taken and statistical analysis revealed from all laboratories that urine samples are significantly more 


\begin{tabular}{|c|c|c|}
\hline Laboratories & Number of isolates & Resistant isolates (\%) \\
\hline $\mathrm{TH}$ & 1515 & $204\left(13.47^{d}\right)$ \\
\hline MDC & 243 & $36\left(14.81^{d}\right)$ \\
\hline PSGL & 1058 & $350\left(33.08^{\mathrm{a}}\right)$ \\
\hline LAGH & 1302 & $298\left(22.89^{\mathrm{C}}\right)$ \\
\hline G2ML & 3978 & $219\left(5.51^{\mathrm{e}}\right)$ \\
\hline HTMC & 2141 & $594\left(27.74^{b}\right)$ \\
\hline
\end{tabular}

Proportions followed by different letters in a column means differences in proportion of resistant isolates at $a<0.05 \%$

Table 2 Repartition of resistant bacteria by sex of patients

\begin{tabular}{llll}
\hline Laboratories & \multicolumn{2}{l}{ Resistant isolates } & P-value \\
\cline { 2 - 3 } & Females (\%) & Males (\%) & \\
\hline TH & $166(81.37)$ & $38(18.63)$ & 0.000001 \\
MDC & $18(50)$ & $18(50)$ & 0.8136 \\
LAGH & $207(69.46)$ & $91(30.54)$ & 0.000001 \\
\hline
\end{tabular}

TH Trust Hospital, MDC Mediplast Diagnostic Center, LAGH LA General Hospital

contaminated with antibiotic resistant bacteria than all other sample types $(\mathrm{P}<0.05$, Additional file 1$)$.

Samples were taken from female and male patients in all the six study areas but only three provided data on sex groups. A two by two comparison revealed for $\mathrm{TH}$ and LAGH that female gender is significantly associated with infection by antibiotic resistant bacteria compared to males $(\mathrm{P}<0.05$, Table 2$)$. MDC had equal proportions $(50 \%)$ of resistant bacteria from male and female patients (Table 2).

The predominant resistant bacterial species varied from one lab to the other, but E. coli and Staphylococcus were the main isolates from all the laboratories. From $\mathrm{TH}$ and G2ML, E. coli were the most recovered isolates (47.5\%, $\mathrm{n}=204$ and $38.4 \%, \mathrm{n}=219$, respectively). However, $S$. aureus prevailed in isolates recovered at MDC, PSGL and LAGH (22.2\%, $\mathrm{n}=36 ; 50.9 \%, \mathrm{n}=350$ and $29.5 \%, \mathrm{n}=298$, respectively). Undistinguished resistant Staphylococcus species were the most common isolates from HTMC (44.8\%, $\mathrm{n}=594$ ) (Table 3).

Records of the bacterial species and their resistance pattern can be found in Additional file 2. Here we summarized the antibiotic resistance profile of the three predominant resistant isolates from each laboratory. At $\mathrm{TH}$, E. coli, Enterococcus faecalis and Klebsiella spp were resistant to AMP, COT, AMC, NAL, TET, CRO, GEN, LEV, NOR, CXM, NTD and CTZ at varying proportions. At MDC, S. aureus, E. coli and Enterobacter spp displayed resistance of varying degrees to AMP, COT, TET,
CIP, NOR, CHL and CXM. Data from PSGL show that S. aureus, E. coli and Pseudomonas spp demonstrated resistance to CEF, PIP, CHL, CTX, AMK, GEN, NAL, CFT, AUG, CIP, TET, NIT, VAN, CTR, MEM, COT, ERY AMP and CRX. From LAGH, the predominant isolates (S. aureus, E. coli and Pseudomonas spp) were resistant to COT, CIP, GEN, AMP, MEM, TET, CRX, AMK, LEV, CTR and CTX. At G2ML S. aureus, E. coli and Citrobacter spp showed resistance against GEN, CIP, AMP, AUG, COT, CRX, TET, CFT, PIP, NAL, CTX, CTR and CHL. The three predominant isolates (E. coli, Staphylococcus spp and Citrobacter freundi) from HTMC were resistant to CPZ, CIP, CTR, PIP, CTX, TET, LEV, GEN, NX, AMK, NA, AMP, OF, CHL, CXM, COT, NIT, AMX, ERY, LM, RO and AZM with different proportions (Additional file 2).

\section{Discussion}

Antibiotic resistant bacterial infections have become a threat, in particular in developing countries, but to obtain an effective treatment plan, it is vital to have an overview of the current resistance level. In this study, data on culture and sensitivity results from six microbiology laboratories were extracted. Within the entire period, each of the six laboratories reported varying numbers of antibiotic resistant bacteria strains ranging from 36 to 594 resistant isolates. Statistical analysis revealed that samples from PSGL generated the highest proportions of resistant isolates (33.08\%). There is therefore a possibility that patients living around or attending PSGL are likely to be more infected with antibiotic resistant bacteria, as it is situated in a densely populated area of residence, compared to patients who attended the other laboratories. Isolates recovered at G2ML, located in an area which primarily covers a business district, demonstrated the lowest level of antibiotic resistance as compared to the rest (5.51\%). Among the six labs, 19 different types of clinical specimen were processed, but the highest level of antibiotic resistant bacteria was found in the urine samples in all laboratories. The proportions of resistant isolates ranged from $37.9 \%$ and up to $69.1 \%$. High level resistance $(66.7 \%)$ in urine has also been shown at the Korle$\mathrm{Bu}$ Teaching Hospital in Ghana [13]. In Sierra Leone $85.7 \%$ of multidrug resistant isolates were identified in urine specimen [14]. Furthermore, the most prevailing resistant bacteria isolated from the various specimens in all the laboratories were E. coli and Staphylococcus. E. coli is the primary etiologic agent causing urinary tract infection, accounting for $90 \%$ of the cases [15], however, in this study we did not acquire data on disease state of patients. But our data showed that female patients from TH (81.37\%) and LAGH (69.46\%) had the highest level of resistant bacteria compared to males. That 
Table 3 Proportion of resistant bacterial species isolated from clinical samples from each laboratory

\begin{tabular}{|c|c|c|c|c|c|c|}
\hline Resistant isolates & $\begin{array}{l}\text { TH } \\
\text { Number (\%) }\end{array}$ & $\begin{array}{l}\text { MDC } \\
\text { Number (\%) }\end{array}$ & $\begin{array}{l}\text { PSGL } \\
\text { Number (\%) }\end{array}$ & $\begin{array}{l}\text { LAGH } \\
\text { Number (\%) }\end{array}$ & $\begin{array}{l}\text { G2ML } \\
\text { Number (\%) }\end{array}$ & $\begin{array}{l}\text { HTMC } \\
\text { Number (\%) }\end{array}$ \\
\hline Providencia spp. & NR & NR & NR & NR & NR & $53(8.9)$ \\
\hline M. morganii & $N R$ & NR & NR & $\mathrm{NR}$ & $N R$ & $3(0.5)$ \\
\hline Citrobacter spp. & NR & $1(2.8)$ & $1(0.3)$ & $17(5.7)$ & $23(10.5)$ & NR \\
\hline S. aureus & $21(10.3)$ & $8(22.2)$ & $178(50.9)$ & $88(29.5)$ & $28(12.8)$ & NR \\
\hline Pseudomonas spp. & $16(7.8)$ & $3(8.3)$ & $13(3.7)$ & $29(9.7)$ & $25(11.4)$ & $7(1.2)$ \\
\hline S. epidermidis & $3(1.5)$ & $4(11.1)$ & $1(0.3)$ & $1(0.3)$ & $6(2.7)$ & NR \\
\hline K.pneumoniae & NR & $1(2.8)$ & NR & $1(0.3)$ & NR & NR \\
\hline P. aeruginosa & NR & $1(2.8)$ & $3(0.9)$ & $18(6.0)$ & $14(6.4)$ & $12(2.0)$ \\
\hline Enterobacter spp. & $6(2.9)$ & $5(13.9)$ & NR & $12(4.0)$ & $3(1.4)$ & $23(3.9)$ \\
\hline N.gonorrhoea & $4(2.0)$ & $2(5.6)$ & $N R$ & NR & $12(5.5)$ & NR \\
\hline E. coli & $97(47.5)$ & 7 (19.4) & $120(34.3)$ & $6.8(22.8)$ & $84(38.4)$ & $86(14.5)$ \\
\hline Y.pestis & NR & $1(2.8)$ & $N R$ & $N R$ & NR & NR \\
\hline S.pyogenes & NR & NR & NR & NR & NR & $2(0.3)$ \\
\hline Proteus spp. & $5(2.5)$ & $2(5.6)$ & $7(2.0)$ & $17(5.7)$ & NR & $4(0.7)$ \\
\hline Klebsiella spp. & $25(12.3)$ & $1(2.8)$ & $4(1.1)$ & $20(6.7)$ & $1(0.5)$ & $12(2.0)$ \\
\hline P. vulgaris & NR & NR & $8(2.3)$ & $N R$ & $1(0.5)$ & NR \\
\hline S. saprophyticus & $\mathrm{NR}$ & $N R$ & $7(2.0)$ & $6(2.0)$ & NR & NR \\
\hline E. faecalis & $27(13.2)$ & NR & $7(2.0)$ & $N R$ & $N R$ & NR \\
\hline P. mirabilis & NR & NR & $1(0.3)$ & $8(2.7)$ & $2(0.9)$ & NR \\
\hline Enterococcus spp. & NR & $N R$ & NR & $6(2.0)$ & $14(6.4)$ & $31(5.2)$ \\
\hline Acinetobacter spp. & NR & NR & $N R$ & $1(0.3)$ & $1(0.5)$ & NR \\
\hline Bacillus spp. & NR & $N R$ & NR & $3(1.0)$ & NR & $1(0.2)$ \\
\hline Streptococcus spp. & NR & NR & NR & $2(0.7)$ & $5(2.3)$ & NR \\
\hline Salmonella spp. & NR & NR & NR & $1(0.3)$ & NR & NR \\
\hline Staphylococcus spp. & NR & NR & NR & $N R$ & NR & $266(44.8)$ \\
\hline C. freundii & NR & NR & NR & NR & NR & $94(15.8)$ \\
\hline
\end{tabular}

NR not reported, TH Trust Hospital, MDC Mediplast Diagnostic Center, PSGL Patholab Solutions (Ghana) Limited, LAGH LA General Hospital, G2ML G2 Medical Laboratory Service, HTMC Holy Trinity Medical Centre

significantly more resistant bacteria were found in female urine samples correlates with a higher susceptibility of infection in females than males, due to the physiological and anatomical differences. Resistant Staphylococcus aureus recovered from various specimens were found in the range $10.3-50.9 \%$. The undistinguished Staphylococcus spp. (44.8\%) from HTMC laboratory may be due to lack of special media or other requirements for accurate and definitive identification. High level antibiotic resistant $S$. aureus has previous been shown in other studies from Ghana and Ethiopia [5, 16, 17]. Often, high levels of $S$. aureus are isolated from different sites of infection, probably due to the fact that this bacterium is part of the normal flora on skin and gut, but can infect breaches on the skin. Moreover, S. aureus is often found at the hospital settings, increasing the risk of infections. Due to the known risk of bacterial spread at hospitals, and lack of typing data, we cannot rule out that some of the resistant bacteria isolated from different specimen may in fact be the same clone.
Gram-negative bacteria accounted for $65.4 \%$ of the resistant bacteria, whereas Gram-positive accounted for 34.6\%. Overall, S. aureus, E. coli, Citrobacter spp., Pseudomonas spp. and Enterobacter spp. from all the laboratories, showed high resistance against tetracycline, ampicillin and cotrimoxazole. Similar report of high resistance to these antibiotics in Ghana has previously been reported $[5,18]$. They are also regarded as the most widely used antibiotics in developing countries, as they are considered inexpensive and generally have broad-spectrum activity [19]. We also observed high resistance of Klebsiella spp. to ceftriaxone and cefuroxime, which has also been observed in a recent study from Rwanda [20]. But the resistance to amoxiclav, amikacin and chloramphenicol was low across most of the laboratories except at G2ML where resistance towards amoxiclav (augmentin) was mostly high. 


\section{Conclusion}

Our analysis of the culture and sensitivity test results of the various species of bacteria isolated from different clinical specimens at various microbiology laboratories revealed that high levels of resistant bacteria were recovered from urine specimens. Furthermore, resistant E. coli and Staphylococcus species were the most prevalent isolates recovered from all the specimens. Specimen from female patients presented the highest prevalence of resistant bacteria isolates as compared to male patients. We observed high resistance to tetracycline, ampicillin, cotrimoxazole and the cephalosporins, but low resistance to amoxiclav and the aminoglycosides. The variations in resistance pattern of the bacterial isolates across the laboratories suggests that regular surveillance and local susceptibility pattern is extremely important in selecting the most appropriate and effective antibiotic for the treatment of bacterial infections.

\section{Limitations of the study}

Our study have some limitations due to lack of information on the disease status of the patients, and it is possible that different specimens were collected from the same patient, resulting in isolation of the same bacterial species.

\section{Additional files}

Additional file 1. Antibiotic resistant bacteria isolated from different sample types at the six laboratories. Total number and percentage of resistant bacterial isolates from each type of specimen isolated at TH (Trust Hospital); MDC (Mediplast Diagnostic Center); PSGL (Patholab Solutions Ghana Limited); LAGH (LA General Hospital); G2ML (G2 Medical Laboratory); HTMC (Holy Trinity Medical Center)

Additional file 2. List of isolates and proportion (\%) of resistance against each tested antibiotic. Data shown for each laboratory. Total list of all bacteria isolated at the six laboratories and the percentage of resistant bacteria against all tested antibiotics. TH (Trust Hospital); MDC (Mediplast Diagnostic Center); PSGL (Patholab Solutions Ghana Limited); LAGH (LA General Hospital); G2ML (G2 Medical Laboratory); HTMC (Holy Trinity Medical Center)

\section{Abbreviations}

TH: Trust Hospital; MDC: Mediplast Diagnostic Center; PSGL: Patholab Solutions Ghana Limited; LAGH: LA General Hospital; G2ML: G2 Medical Laboratory; HTMC: Holy Trinity Medical Center; AMR: antimicrobial resistance; SPSS: statistical package for social sciences; AMP: ampicillin; COT: cotrimoxazole; AMC: amoxiclav; NAL: nalidixic acid; TET: tetracycline; CTR: ceftriaxone; CAZ: ceftazidime; NIT: nitrofurantoin; GEN: gentamicin; CIP: ciprofloxacin; LEV: levofloxacin; NOR: norfloxacin; CHL: chloramphenicol; CRX: cefuroxime; AMK: amikacin; PIP: piperacillin; NTD: nitrofurandantoin; CTX: cefotaxime; P: penicillin; FLX: flucloxacillin; ERY: erythromycin; AMX: amoxicillin; OF: ofloxacin; CLX: cloxacillin; PEF: perfloxacin; AUG: augmentin; VAN: vancomycin; MEM: meropenem; RO: roxithromycin; SPX: sparfloxacin; LM: lincomycin; AZM: azithromycin; PPA: pipemidic acid.

\section{Authors' contributions}

JM, YMGH and LET conceived and designed the study; JM collected the data; $J M, Y M G H$ and LET analyzed the data; JM, YMGH and LET wrote the manuscript. All authors read and approved the final manuscript.

\section{Author details}

${ }^{1}$ Department of Microbiology, Parasitology and Biotechnology, College of Veterinary Medicine and Biomedical Sciences, Sokoine University of Agriculture, Morogoro, Tanzania. ${ }^{2}$ Department of Veterinary and Animal Sciences, Faculty of Health and Medical Sciences, University of Copenhagen, 1870 Frederiksberg, Denmark.

\section{Acknowledgements}

The authors wish to express their profound gratitude to the following people for providing the vital support in granting us with the data needed for carrying out this study: Mr. Richard Sreboe (Chief Biomedical Scientist), Trust Specialist Hospital (OSU); Mr. John Ani-Amponsah (Chief Executive Officer) and Miss Ruthana Owusua (Medical Lab Technician), Mediplast Diagnostic Center; Mr. Gershon Sekley (Chief Executive Officer), G2 Medical Laboratories; Mr. Geoffrey R. Atelu (Chief Biomedical Scientist), LA General Hospital; Mr. Alexander Murphy Foli (Chief Biomedical Scientist), Patholab Solutions Ghana Limited and Mr. Theophilus Dodoo (Chief Biomedical Scientist), Holy Trinity Medical Center.

\section{Competing interests}

The authors declare that they have no competing interests.

\section{Availability of data and materials}

The datasets supporting the conclusions of this article are included within the article and its additional files.

\section{Consent for publication}

Not applicable.

\section{Ethical approval and consent to participate}

This is a retrospective study, which involve collection of data covering bacterial cultures and their antimicrobial sensitivity, without access to patient information. The study was part of routine surveillance in the Accra area and letter of consent for using data exist from the six laboratories. The study outcome will be available to the laboratories/hospitals to help formulate guidelines for treatments.

\section{Funding}

Not applicable.

\section{Publisher's Note}

Springer Nature remains neutral with regard to jurisdictional claims in published maps and institutional affiliations.

Received: 6 February 2018 Accepted: 21 April 2018

Published online: 25 April 2018

\section{References}

1. Kimanga AN. A situational analysis of antimicrobial drug resistance in Africa: are we losing the battle? Ethiop J Health Sci. 2012;22(2):135-43.

2. Antimicrobial Research Council. Antimicrobial resistance. 2014. http:// www.mrc.ac.uk/documents/pdf/antimicrobial-resistance-timeline-repor t/. Accessed 4 Aug 2017.

3. Shankar RP, Partha P, Shenoy NK, Easow JH, Brahmadathan KN. Prescribing patterns of antibiotics and sensitivity patterns of common microorganisms in the Internal Medicine ward of a teaching hospital in Western Nepal: a prospective study. Ann Clin Microbiol Antimicrob. 2003;2:7.

4. Vialle-Valentin CE, Lecates RF, Zhang F, Desta AT, Ross-Degnan D. Predictors of antibiotic use in African communities: evidence from medicines household surveys in five countries. Trop Med Int Health. 2012;17(2):211-22.

5. Newman MJ, Frimpong E, Donkor ES, Opintan J. Resistance to antimicrobial drugs in Ghana. Infect Drug Resist. 2011;4:215-20. 
6. Dada-Adegbola H, Muili K. Antibiotic susceptibility pattern of urinary tract pathogens in Ibadan, Nigeria. Afr J Med Sci. 2010;39(3):173-9.

7. Andabati G, Byamugisha J. Microbial aetiology and sensitivity of asymptomatic bacteriuria among ante-natal mothers in Mulago hospital, Uganda. Afr Health Sci. 2010;10(4):349-52.

8. Moyo S, Aboud S, Kasubi M, Maselle SY. Bacteria isolated from bloodstream infections at a tertiary hospital in Dar es Salaam, Tanzania-antimicrobial resistance of isolates. S Afr Med J. 2010;100(12):835-8.

9. Mbanga J, Dube S, Munyanduki H. Prevalence and drug resistance in bacteria of the urinary tract infections in Bulawayo province, Zimbabwe. East Afr J Public Health. 2010;7(3):229-32.

10. Cheesbrough M. District laboratory practice in tropical countries. 2nd ed. Cambridge: Cambridge University Press; 2006.

11. Bauer A, Kirby W, Sherris J, Turck M. Antibiotic susceptibility testing by a standardized single disk method. Am J Clin Pathol. 1966;45(4):493-6.

12. Institute Clinical Laboratory Standard. Twentey-fourth informational supplement. Wayne: CLSI; 2014.

13. Obeng-nkrumah N, Twum-danso K, Krogfelt KA, Newman MJ. High levels of extended-spectrum beta-lactamases in a major teaching hospital in Ghana: the need for regular monitoring and evaluation of antibiotic resistance. Am J Trop Med Hyg. 2013;89(5):960-4.

14. Leski TA, Taitt CR, Bangura U, Stockelman MG, Ansumana R, Cooper WH 3rd, Stenger DA, Vora GJ. High prevalence of multidrug resistant Enterobacteriaceae isolated from outpatient urine samples but not the hospital environment in Bo, Sierra Leone. BMC Infect Dis. 2016;16:167.
15. Demilie T, Beyene G, Melaku S, Tsegaye W. Urinary bacterial profile and antibiotic susceptibility pattern among pregnant women in North West Ethiopia. Ethiop J Health Sci. 2012;22(2):121.

16. Nkrumah NO, Labi AK, Addison NO, Ewuramma J, Labi M, Mensah GA. Trends in paediatric and adult bloodstream infections at a Ghanaian referral hospital: a retrospective study. Ann Clin Microbiol Antimicrob. 2016;15:49.

17. Mulu W, Abera B, Yimer M, Hailu T, Ayele H, Abate D. Bacterial agents and antibiotic resistance profiles of infections from different sites that occurred among patients at Debre Markos Referral Hospital, Ethiopia: a cross sectional study. BMC Res Notes. 2017;10(1):254.

18. Hackman HK, Brown CA, Twum-danso K. Antibiotic resistance profile of non-extended spectrum beta-lactamase-producing Escherichia coli and Klebsiella pneumoniae in Accra, Ghana. J Biol Agric Health. 2014;4(14):12-7.

19. Lerbech AM, Opintan JA, Bekoe SO, Ahiabu MA, Tersbøl BP, Hansen M, Brightson KT, Ametepeh S, Frimodt-Møller N, Styrishave B. Antibiotic exposure in a low-income country: screening urine samples for presence of antibiotics and antibiotic resistance in coagulase negative staphylococcal contaminants. PLOS ONE. 2014:9(12):e113055.

20. Ntirenganya C, Manzi O, Muvunyi CM, Ogbuagu O. High prevalence of antimicrobial resistance among common bacterial isolates in a tertiary healthcare facility in Rwanda. Am J Trop Med Hyg. 2015;92(4):865-70.
Ready to submit your research? Choose BMC and benefit from:

- fast, convenient online submission

- thorough peer review by experienced researchers in your field

- rapid publication on acceptance

- support for research data, including large and complex data types

- gold Open Access which fosters wider collaboration and increased citations

- maximum visibility for your research: over 100M website views per year

At BMC, research is always in progress.

Learn more biomedcentral.com/submissions 